\title{
THE EFFECT OF HIGH DOSE AND LOW DOSE PREGABALIN AS PREMEDICATION ON PREOPERATIVE ANXIETY AND SEDATION LEVELS
}

\author{
Ayman Zafar, Kulsoom Farhat, Mobasher Ahmed Saeed*, Waqar Aslam Khan, Shabana Ali, Nausheen Ata \\ Army Medical College/National University of Medical Sciences (NUMS) Rawalpindi Pakistan, *Combined Military Hospital/National University of Medical \\ Sciences (NUMS) Rawalpindi Pakistan
}

\begin{abstract}
Objective: To assess the role of pregabalin as premedication for preoperative sedation and anxiolysis with two different doses in laparoscopic cholecystectomy patients.

Study Design: Quasi-experimental study.

Place and Duration of Study: Department of Pharmacology and Therapeutics, Army Medical College, Rawalpindi in collaboration with Department of Anesthesiology, Combined Military Hospital, Rawalpindi, from Feb to Jul 2019.

Methodology: A total 96 patients of either gender, aged between 18-60 years with American Society of Anesthesiologists (ASA) grade I-II, undergoing elective laparoscopic cholecystectomy were enrolled in this study. They were randomly divided into three groups having 32 patients each. Group 1 received oral placebo drug, group 2 received oral pregabalin 150 $\mathrm{mg}$, whereas group 3 received oral pregabalin $300 \mathrm{mg}$ with sip of water $90 \mathrm{mins}$ before the induction of general anesthesia. The effects of drugs on the patient's level of sedation and anxiety were evaluated at baseline and before the induction of anesthesia using Ramsay Sedation Score and Beck Anxiety Inventory respectively.

Results: Premedication with pregabalin $150 \mathrm{mg}$ and $300 \mathrm{mg}$ significantly produced sedation as compared to placebo. Though, Pregabalin $(300 \mathrm{mg})$ exhibited more sedation than Pregabalin $(150 \mathrm{mg})$ but the difference between them was statistically insignificant $(p=0.33)$. Preoperative administration of pregabalin was related with anxiolysis, with the most prominent results shown by pregabalin $300 \mathrm{mg}(p<0.00)$ whereas pregabalin $150 \mathrm{mg}$ could not alleviate anxiety and the results were statistically insignificant $(p=0.05)$.

Conclusion: Premedication with Pregabalin 300mg, 90 mins before the induction of general anesthesia is an effective regimen to alleviate preoperative anxiety and sedation.
\end{abstract}

Keywords: Anxiolysis, Laparoscopic cholecystectomy, Pregabalin, Premedication, Sedation.

How to Cite This Article: Zafar A, Farhat K, Saeed MA, Khan WA, Ali S, Ata N. The Effect of High Dose and Low Dose Pregabalin as Premedication on Preoperative Anxiety and Sedation Levels. Pak Armed Forces Med J 2021; 71(5): 1759-1763. doi:https://doi.org/10.51253/pafmi.v71i5.3999

This is an Open Access article distributed under the terms of the Creative Commons Attribution License (https://creativecommons.org/licenses/by-nc/4.0/), which permits unrestricted use, distribution, and reproduction in any medium, provided the original work is properly cited.

\section{INTRODUCTION}

Sedation is defined as the administration of a sedative drug to create a state of rest and calmness. Drug induced sedation is a state designed to facilitate procedures and assessment of sedation level of patients deals with their levels of sleep or calmness rather than their levels of consciousness. Preprocedural and procedural sedation are used to minimize the discomfort associated with painful and invasive procedures ${ }^{1}$.

Preoperative anxiety is a type of state anxiety which arises due to fear of surgical procedure. Preoperative anxiety is a real concern for many patients undergoing anesthesia and surgery. Literature reports that $60-92 \%$ of patients experience significant preoperative anxiet ${ }^{2}$. It starts immediately after the surgery is planned and peaks at a day of surgery. The stress of going into surgery and postoperative outcomes, failures and

Correspondence: Dr Ayman Zafar, Department of Pharmacology, Army Medical College, Abid Majeed Road, Rawalpindi Pakistan Received: 12 Mar 2020; revision received: 01 Oct 2020; accepted: 05 Oct 2020 complications can create feeling of nervousness and anxiety. It potentially alters the patients hemodynamics by increasing circulating Catecholamines, producing cognitive and psychological discomfort, along with increased in body temperature, nausea, sweating, increased sense of smell and touch ${ }^{3}$. Preoperative anxiety is strongly correlated to patient's dissatisfaction after surgical procedure. Anesthetists find it challenging on the account of preoperative anxiety that include difficult venous access, delayed jaw relaxation and coughing during induction of anesthesia and intraoperative hemodynamic instability due to autonomic fluctuations. This anxiety state also leads to rise in plasma Catecholamines level adding in the burden of patients's hemodynamic response ${ }^{4}$. Literature has shown that anxious patients undergoing surgery usually demand more anesthesia. It will affect the surgery as well as the recovery and post-operative outcomes ${ }^{5}$. Furthermore, preoperative anxiety also influences pain, stress, anxiety and analgesic requirement in the postoperative period which leads to prolong hospital 
stay. Although benzodiazepines (BZD) are given preoperatively to produce sedation and reduce anxiety but these are associated with negative effects like excessive drowsiness, respiratory depression, emergence delirium, delay recovery, drug interaction with anesthetic drugs and prolonged hospital stay ${ }^{6}$. Anxiolytic premedication is given not only to relieve anxiety but it also produces sedation and improved patients satisfaction level.

Pregabalin (PGB) is a structural analogue of gamma-amino butyric acid (GABA). Literature shows that it has anticonvulsant, analgesic, sleep-modulating and anxiety relieving properties. It binds to the alpha2-delta (a2- $\delta$ ) auxiliary protein with great affinity. $a 2-\delta$ ligand is involved in the influx of calcium $\left(\mathrm{Ca}^{++}\right)$at presynaptic voltage-sensitive calcium channels ${ }^{7}$. PGB reduces depolarization-induced $\mathrm{Ca}^{++}$entry via presynaptic $\mathrm{Ca}^{++}$channels in the central nervous system (CNS) ${ }^{8}$. The release of numerous excitatory neurotransmitters is reduced including glutamate, calcitonin gene related peptide (CGRP), norepinephrine (NE) and substance $p$, thus producing inhibitory modulation of overexcited neurons and returning them to a normal level ${ }^{9}$. It does not produce any effect after binding to GABAA, GABAB or BZD receptors. The pharmacokinetic profile of PGB is well tolerable after oral administration and peak serum concentration is seen after 1 hour (h) of drug administration ${ }^{10}$.

However, few recent research suggests that administration of PGB preoperatively is an effective approach for preoperative anxiolysis and sedation. Only minimal evidence is available in our literature related to the sedative and anxiolytic activities of PGB in patients undergoing laparoscopic surgery. Hence, the present study was designed to evaluate the effects of oral PGB on anxiolysis and sedation in patients undergoing laparoscopic cholecystectomy.

\section{METHODOLOGY}

This quasi-experimental study was conducted in department of Pharmacology and Therapeutics at Army Medical College, Rawalpindi in collaboration with Combined Military Hospital (CMH), Rawalpindi. Using WHO calculator, sample size was calculated as follows: Level of significance $(\%)=5$, Power of the test $(\%)=80$ and for the detection of clinically meaningful reduction in anxiety $20 \%$ and $10 \%$ dropout rate was anticipated ${ }^{11,12}$, the final sample size was 32 patients in each group, which permitted a type I error of $\alpha=0.05$, a type II error of $\beta=0.5$. After obtaining approval by ethical review committee (ERC) of AMC (CREAM)
(Ref ltr dated May 3, 2019) and CMH, Rawalpindi, 96 patients were enrolled in this study via non-probability consecutive sampling technique and then simple random method was used for allocation of patients in study groups.

Inclusion Criteria: Patients of either gender, aged between 18-60 years with ASA grade I \& II undergoing elective laparoscopic cholecystectomy were enrolled in this study.

Exclusion Criteria: Patients who had any history of drug abuse or were taking any antidepressant, anticonvulsants, sedative, hypnotic or antipsychotics were not the part of this study. Patients were excluded if they had ASA grade III \& IV with difficult (Mallampati score $\geq 3$ ) and prolong intubation (>20 sec) or multiple attempts (>1 attempts) for laryngoscopy along with known drug allergy, had any clinically significant neuropsychiatric conditions, had pregnancy or lactating females.

Patients fulfilling the inclusion criteria were enrolled in the study and written informed consent was obtained. After explaining the whole study protocol, patients were randomly assigned to one of the three study groups using lottery method and drugs were administered according to following intervention protocol. Group 1, control group received an oral placebo drug, Group 2 received PGB $150 \mathrm{mg}$ orally and Group 3 received PGB $300 \mathrm{mg}$ orally with a sip of water 90

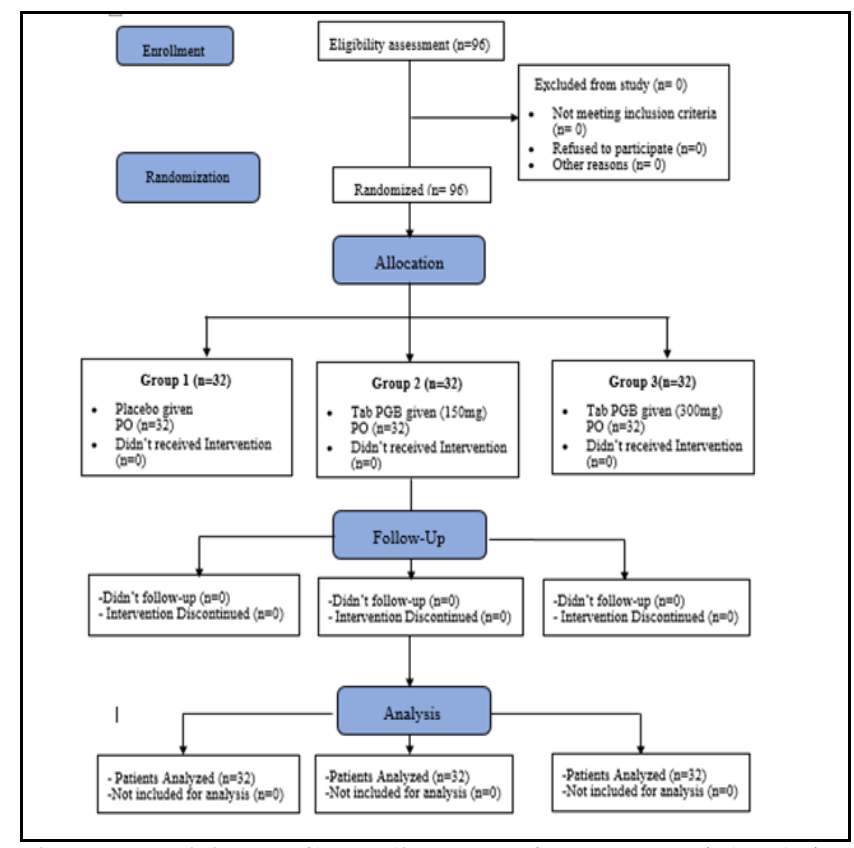

Figure: Participant flow diagram of Group 1 (Placebo); Group 2 (PGB 150mg); Group 3 (300mg). 
mins prior to the induction of general anesthesia. Participant flow diagram of this experimental study was shown in Figure.

In the preoperative holding area, the patients assessed their level of sedation using Ramsay sedation score (RSS) ranging from 1-6 (1, anxious or restless; 2 , cooperative/oriented; 3 , responding to commands; 4 , brisk response to stimulus; 5, sluggish response to stimulus; and 6, no response to stimulus) ${ }^{11}$. The high sedation score shows increase in sedation level. Anxiety status was evaluated via beck anxiety inventory (BAI) having 21 descriptive statements that asked about anxiety symptoms of patients before surgery. Each statement was answered against the Likert scale of four points: $0=$ "absolutely not"; $1=$ "slightly, not bothering me too much"; $2=$ "moderately, its unpleasant, but bearable"; or 3,="unbearable"12. Adding the sum of 21 statements showed the total anxiety score of the patient, which was between 0-63. Score was further categorized into minimum anxiety (Score of 0-10), mild anxiety (Score of 11-19), moderate anxiety (Score of 20-30) and severe anxiety (Score of 31-63) ${ }^{13}$.

Sedation and anxiety level were evaluated before receiving the study medication (T0) and before induction of anesthesia (T1). A uniform anesthetic technique was used in all the patients. In OT, patients were given Inj. Ondansetron $0.1 \mathrm{mg} / \mathrm{kg}$ intravenously (IV). Preoxygenation was done with $100 \%$ oxygen $\left(\mathrm{O}^{2}\right)$ for 3 mins in all patients, after preoxygenation, anesthesia was induce by IV propofol $(2 \mathrm{mg} / \mathrm{kg})$, nalbuphine chloride $(0.1 \mathrm{mg} / \mathrm{kg})$ followed by atracurium $(0.15 \mathrm{mg}$ $/ \mathrm{kg}$ ), a skeletal muscle relaxant, to facilitate endotracheal intubation ${ }^{14}$. The anesthesia was maintained with atracurium, intermittent positive-pressure ventilation (IPPV) N2O:O2-50: 50 and inhalational agent isoflurane at 1.2 Minimum Alveolar Concentration (MAC) and Circle system with CO2 absorber. Pneumoperito- neum was created after insufflation of $\mathrm{CO} 2$ and reverse trendelenburg position was made to facilitate the exposure of gall bladder. Patients were observed for any adverse events perioperatively. At end of surgery, isoflurane was discontinued and inspired $\mathrm{O}^{2}$ flow was increased. The reversal of neuromuscular blockade was carried out with neostigmine $60 \mathrm{mcg}$ and glycopyrrolate $10 \mathrm{mcg} / \mathrm{kg}^{15}$.

Data was analyzed in Statistical Package for Social Sciences (SPSS) version 23. For the interpretation of quantitative variables in demographic data (age \& $\mathrm{BMI})$, mean \pm standard deviation (SD) were calculated. Categorical variables in demographic data like gender and ASA grade were expressed as frequency and percentages (\%). Sedation scores were analyzed by ChiSquare Test whereas anxiety levels were compared via Fisher's Exact Test. The $p$-value $\leq 0.05$ was studied as significant between observations.

\section{RESULTS}

A total of 96 patients fulfilling the inclusion criteria were enrolled to determine the effect of Pregabalin on sedation and anxiety level. The demographic profile of all the three study groups were comparable and there were insignificant differences among the three groups with respect to age, gender, BMI, ASA grade, time interval between study drug administration and induction of anesthesia.

The preoperative sedation scores were evaluated in each group before premedication (T0) and it was comparable in all three groups but the sedation level after premedication (T1) significantly improved in group $2 \& 3$ from their baseline score, received PGB $150 \mathrm{mg} \& 300 \mathrm{mg}$ respectively ( $p$-value $=0.044 \& 0.023$ ) (Table-I). On intergroup comparison of sedation score after premedication between the three groups, PGB $150 \mathrm{mg}$ and $300 \mathrm{mg}$ significantly improved sedation as

Table-I: Comparison of sedation level within study groups.

\begin{tabular}{|c|c|c|c|c|c|c|c|}
\hline \multirow{2}{*}{\multicolumn{2}{|c|}{ Sedation Score }} & \multicolumn{2}{|c|}{$\begin{array}{c}\text { Group } 1 \text { (Placebo) } \\
\text { Frequency }(\%)\end{array}$} & \multicolumn{2}{|c|}{$\begin{array}{c}\text { Group } 2 \text { (PGB 150mg) } \\
\text { Frequency }(\%)\end{array}$} & \multicolumn{2}{|c|}{$\begin{array}{l}\text { Group } 3 \text { (PGB 300mg) } \\
\text { Frequency (\%) }\end{array}$} \\
\hline & & \multirow{2}{*}{$\begin{array}{c}\begin{array}{c}\text { Before } \\
\text { premedication } \\
\text { (T0) }\end{array} \\
15(46.87 \%) \\
\end{array}$} & \multirow{2}{*}{$\begin{array}{c}\begin{array}{c}\text { Before } \\
\text { induction } \\
\text { (T1) }\end{array} \\
21(65.62 \%)\end{array}$} & \multirow{2}{*}{$\begin{array}{c}\begin{array}{c}\text { Before } \\
\text { premedication } \\
\text { (T0) }\end{array} \\
18(56.35 \%) \\
\end{array}$} & \multirow{2}{*}{$\begin{array}{c}\begin{array}{c}\text { Before } \\
\text { induction } \\
\text { (T1) }\end{array} \\
10(31.25 \%)\end{array}$} & \multirow{2}{*}{\begin{tabular}{c|}
$\begin{array}{c}\text { Before } \\
\text { premedication } \\
\text { (T0) }\end{array}$ \\
$16(50 \%)$ \\
\end{tabular}} & \multirow{2}{*}{$\begin{array}{c}\begin{array}{c}\text { Before } \\
\text { induction } \\
\text { (T1) }\end{array} \\
6(18.75 \%)\end{array}$} \\
\hline 1 & Anxious/restless & & & & & & \\
\hline 2 & Cooperative/Oriented & $17(53.12 \%)$ & $11(34.37 \%)$ & $14(43.75 \%)$ & $22(68.75 \%)$ & $16(50 \%)$ & $25(78.12 \%)$ \\
\hline 3 & Responding to commands & - & - & - & - & - & $1(3.12 \%)$ \\
\hline 4 & Brisk response to stimulus & - & - & - & - & - & - \\
\hline 5 & Sluggish response to stimulus & - & - & - & - & - & - \\
\hline 6 & No response to stimulus & - & - & - & - & \begin{tabular}{l|l}
- & \\
\end{tabular} & - \\
\hline \multicolumn{2}{|c|}{$p$-value (intra group) } & \multicolumn{2}{|c|}{$p$-value $=0.131$} & \multicolumn{2}{|c|}{$p$-value $=0.044$} & \multicolumn{2}{|c|}{$p$-value $=0.023$} \\
\hline \multicolumn{2}{|c|}{$\begin{array}{l}p \text {-value } \\
\text { (between two groups) }\end{array}$} & \multicolumn{2}{|c|}{$\begin{array}{l}\text { Gp1 vs Gp2 } 0.006 \\
\text { Gp1 vs Gp3 } 0.001\end{array}$} & \multicolumn{2}{|c|}{$\begin{array}{l}\text { Gp2 vs Gp1 } 0.006 \\
\text { Gp2 vs Gp3 } 0.334\end{array}$} & \multicolumn{2}{|c|}{$\begin{array}{l}\text { Gp3 vs Gp1 } 0.001 \\
\text { Gp3 vs Gp2 } 0.334\end{array}$} \\
\hline
\end{tabular}


compared to placebo ( $p$-value $=0.060 \& 0.001)$. Only $18 \%$ patients in PGB $300 \mathrm{mg}$ and $31 \%$ in PGB $150 \mathrm{mg}$ group were anxious or restless as compared to placebo group having $65 \%$ patients in anxious or restless state. Though PGB 300mg showed more sedation score than PGB 150mg but the difference between the two groups were statistically insignificant (Table-I).

The preoperative anxiety status was evaluated in each group before premedication (T0) and it was comparable in all three groups but the anxiety level after premedication (T1) significantly improved in group 3 from their baseline score, received PGB 300mg ( $p$-value $=0.002$ ) whereas PGB $150 \mathrm{mg}$ also alleviated anxiety from baseline but it was statistically insignificant $(p$ value $=0.055$ ) (Table-II). On inter group comparison of anxiety score after premedication between the three groups, PGB $300 \mathrm{mg}$ significantly produce anxiolytic effects as compared to PGB $150 \mathrm{mg} \&$ placebo ( $p$-value $=0.016 \& 0.002$ respectively). Almost $90 \%$ patients had minimal anxiety in PGB 300 group as compared to PGB $150 \mathrm{mg}$ and placebo which had $65 \%$ and $56 \%$ respectively. Whereas the anxiolytic effect of PGB 150 $\mathrm{mg}$ was more than placebo but the difference between them were statistically insignificant $(p$-value $=0.304)$ (Table-II). gery were comparable and the difference between the three groups were insignificant.

PGB is believed to modulate the activation and release of many excitatory neurotransmitters, leading to a reduction in levels of anxiety ${ }^{9}$. Preclinical data has shown that PGB possess anxiolytic properties. Although few studies on PGB has done in past but the dose ranging study using high and low dose of PGB has not been conducted in laparoscopic cholecystectomy patients in Pakistan. Therefore the administration of PGB before surgery might be an effective anxiolytic with favorable pharmacokinetics and peak plasma concentrations are achieved within 1-2 $\mathrm{h}^{18}$. In our study PGB was administered 90 mins before surgery so that peak plasma levels of PGB has achieved and then sedation and anxiety levels were assessed ${ }^{19}$. In 2018, study revealed that in patients with generalized anxiety disorders (GAD), the chronic use of PGB was significantly more effective than the BDZs (diazepam) in improving anxiety symptoms ${ }^{20}$. Recently in 2019 another study compared PGB 75mg with Alprazolam 0.5mg and concluded that both drugs had equally reduced anxiety ${ }^{21}$. In our study the highest dose of PGB $(300 \mathrm{mg})$ reduced anxiety prominently $(p$-value $<0.05)$ after premedication before elective laparoscopic cholecystectomy as

Table-II: Comparison of anxiety level within study groups.

\begin{tabular}{|c|c|c|c|c|c|c|c|}
\hline \multirow{2}{*}{\multicolumn{2}{|c|}{ Anxiety Score }} & \multicolumn{2}{|c|}{$\begin{array}{l}\text { Group } 1 \text { (Placebo) } \\
\text { Frequency }(\%)\end{array}$} & \multicolumn{2}{|c|}{$\begin{array}{c}\text { Group } 2 \text { (PGB 150mg) } \\
\text { Frequency ( } \%)\end{array}$} & \multicolumn{2}{|c|}{$\begin{array}{c}\text { Group } 3 \\
\text { Frequency }(\%)\end{array}$} \\
\hline & & \multirow{2}{*}{$\begin{array}{c}\begin{array}{c}\text { Before } \\
\text { premedication } \\
\text { (T0) }\end{array} \\
20(62.5 \%) \\
\end{array}$} & \multirow{2}{*}{\begin{tabular}{|c|}
$\begin{array}{c}\text { Before } \\
\text { induction (T1) }\end{array}$ \\
$18(56.25 \%)$ \\
\end{tabular}} & \multirow{2}{*}{$\begin{array}{c}\begin{array}{c}\text { Before } \\
\text { premedication } \\
\text { (T0) }\end{array} \\
13(40.62 \%) \\
\end{array}$} & \multirow{2}{*}{\begin{tabular}{|c|}
$\begin{array}{c}\text { Before } \\
\text { induction (T1) }\end{array}$ \\
$21(65.62 \%)$ \\
\end{tabular}} & \multirow{2}{*}{$\begin{array}{c}\begin{array}{c}\text { Before } \\
\text { Premedication } \\
\text { (T0) }\end{array} \\
16(50 \%) \\
\end{array}$} & \multirow{2}{*}{$\begin{array}{c}\begin{array}{c}\text { Before } \\
\text { Induction (T1) }\end{array} \\
29(90.62 \%) \\
\end{array}$} \\
\hline $0-10$ & Minimal anxiety & & & & & & \\
\hline $11-19$ & Mild anxiety & $9(28.12 \%)$ & $14(43.75 \%)$ & $16(50 \%)$ & $11(34.37 \%)$ & $14(43.75 \%)$ & $3(9.37 \%)$ \\
\hline $20-30$ & Moderate anxiety & $3(9.37 \%)$ & - & $3(9.37 \%)$ & - & $2(6.25 \%)$ & - \\
\hline $31-63$ & Severe anxiety & - & - & - & - & - & - \\
\hline \multicolumn{2}{|c|}{$p$-value (intra group) } & \multicolumn{2}{|c|}{$p$-value $=0.123 \#$} & \multicolumn{2}{|c|}{$p$-value $=0.055^{*}$} & \multicolumn{2}{|c|}{$p$-value $=0.002^{*}$} \\
\hline \multicolumn{2}{|c|}{$\begin{array}{l}p \text {-value } \\
\text { (between two groups) }\end{array}$} & \multicolumn{2}{|c|}{$\begin{array}{l}\text { Gp1 vs Gp2 0.304\# } \\
\text { Gp1 vs Gp3 0.002* }\end{array}$} & \multicolumn{2}{|c|}{$\begin{array}{l}\text { Gp2 vs Gp1 0.304\# } \\
\text { Gp2 vs Gp3 } 0.016^{*}\end{array}$} & \multicolumn{2}{|c|}{$\begin{array}{l}\text { Gp3 vs Gp1 } 0.002^{*} \\
\text { Gp3 vs Gp2 } 0.016^{*}\end{array}$} \\
\hline
\end{tabular}

\section{DISCUSSION}

Most patients awaiting elective surgery experience the preoperative anxiety. Sedative premedication can effectively alleviate anxiety as well as produce calmness in patients ${ }^{16,17}$. The use of preoperative BDZs is the most common practice to decrease preoperative anxiety but they do not have a positive effect on the postoperative outcome 7 .

Previously preoperative anxiety levels have been linked to age, gender, BMI and type and duration of surgical procedures, but in our study these demographic factors like gender, age, duration and type of sur- compared to low dose PGB (150mg) and placebo. These results are similar to the results concluded by Polat et al, according to him preoperative administration of PGB produced significant anxiolysis as compared to placebo ${ }^{22}$. Singh and his colleagues evaluated a role of PGB $150 \mathrm{mg}$ as premedication and found it having anxiolytic properties ${ }^{7}$. In contrast to this, another study evaluated role of PGB as premedication for anxiolysis using $75 \mathrm{mg}, 150 \mathrm{mg}$ and $300 \mathrm{mg}$ but he concluded that all doses of PGB were ineffective in alleviating preoperative anxiety ${ }^{23}$. This could probably be due to short time interval between drug administration and 
induction of general anesthesia (60 mins) in his study protocol.

PGB is an easily tolerated drug with limited adverse effects and low potential for interaction with other drugs. Some of the adverse effects reported are somnolence, dizziness, confusion, headache and weight gain usually after long-term use. The most common adverse effects for postoperative patients were dizziness, somnolence, and sedation. In our study, we considered its sedative effect as an advantage for patients undergoing surgery so we included it in our measurements and no other adverse effects were reported.

In our study administration of PGB produce calmness in patients and induced sedation as compared to placebo ( $p$-value $>0.05$ ). About $150 \mathrm{mg}$ and $300 \mathrm{mg}$ of PGB equally produced sedation with insignificant difference between them ( $p$-value $>0.05$ ).

When focusing on perioperative sedation, current study revealed a significant difference in Ramsay sedation score $(p$-value $<0.05)$ when patients receiving sin-gle dose of $150 \mathrm{mg}$ and $300 \mathrm{mg}$ of PGB as compared to control group, with patients taking 150mg PGB showed similar sedative properties as that of PGB $300 \mathrm{mg}$. Our results were consistent with some recent studies compared PGB $75 \mathrm{mg}$ and $150 \mathrm{mg}$ and showed better and prolong sedation with higher dose of PGB ${ }^{24}$. Ibrahim et al used PGB as premedication and concluded that administration of PGB before surgery reduce the consumption of sedatives before bronchoscopy ${ }^{25}$. Another study compared high (300mg) and low $(150 \mathrm{mg})$ dose of PGB and stated that both drugs equally produced sedation.

\section{CONCLUSION}

Pretreatment with $150 \mathrm{mg} \& 300 \mathrm{mg}$ of PGB before surgery significantly enhanced sedation but $300 \mathrm{mg}$ of PGB has prominent anxiolytic effects than 150mg of PGB when given to the patients undergoing laparoscopic cholecystectomy. We suggest that PGB 300mg may therefore be considered as a possible premedicant in patients undergoing elective surgery. However, further powered clinical investigations should be done to support the current study outcomes.

\section{Conflict of Interest: None.}

\section{Authors' Contribution}

AZ: Study design, literature review and results compilation, KF: Methodology, results compilation, MAS: Study design, datal collection, WAK: Data analysis, proof reading, SA: Study design, biostatistics, NA: Data analysis.

\section{REFERENCES}

1. Rasheed A, Amirah M, Abdallah M, Parameaswari P, Issa M, Ramsay sedation scale (RSS) and richmond agitation sedation scale (RASS): a cross sectional study. Health Sci J 2018; 12(6): 1-5.

2. Jiwanmall M, Jiwanmall SA, Williams A, Kamakshi S, Sugirtharaj L. Preoperative anxiety in adult patients un-dergoing day care surgery: Prevalence and associated factors. Indian J Psychol Med 2020; 42(1): 87-92.

3. Tulloch I, Rubin JS. Assessment and management of preoperative anxiety. J Voice 2019; 33(5): 691-696.
4. Kumar A, Dubey PK, Ranjan A. Assessment of anxiety in surgical patients: an observational study. Anes Essays Res 2019; 13(3): 503-510.

5. Gebhardt V, Kiefer K, Weiss C, Schmittner MD. Influence of anxiolytic premedication on vasovagal reactions and home readiness following outpatient intrathecal anaesthesia-A retrospective analysis. Acta Anaesthesiol Scand 2019; 63(4): 468-474.

6. Gu X, Tan XJ, Guo YX, Cai S, Chen J, Zhang L. The effects of intranasal dexmedetomidine premedication on sedation and stress of tracheal intubation in patients undergoning gynecologi-cal laparoscopic surgery. Biomed J Sci Tech Res 2019; 21(5): 16270-16275.

7. Singh D, Yadav JS, Jamuda BK, Singh P. Oral pregabalin as premedication on anxiolysis and stress response to laryngoscopy and endotracheal intubation in patients undergoing laparoscopic cholecystectomy: A randomized double-blind study. Anes Essays Res 2019; 13(1): 97-102.

8. Karube N, Ito S, Sako S, Hirokawa J. Sedative effects of oral pre-gabalin premedication on intravenous sedation using propofol target-controlled infusion. J Anes 2017; 31(4): 586-592.

9. Park KD, Kim MK, Lee SJ. Negative myoclonus associated with pregabalin. Yeung Uni J Med 2018; 35(2): 240-245.

10. Meena R, Meena K, Prakash S. Study of Attenuation of car-diovascular response during laryngoscopy and intubation using two different doses of pregabalin as premedication in controlled hypertensive patients-a randomized control trial. J Anes Clin Res 2016; 7(2): 1-6.

11. Jokelainen J, Mustonen $H$, Kylänpää L, Udd M, Lindström O. Assessment of sedation level for endoscopic retrograde cholangiopancreatography - A prospective validation study. Scand J Gastroenterol 2018; 53(3): 370-375.

12. Acikalin RM, Haci C, Altin F. Is there any effect of anxiety and depression scores on the improvement of tinnitus after surgery in chronic otitis patients with tinnitus?. Am J Otolaryngol 2018; 40(2019): 230-232.

13. Lemos MF, Lemos-Neto SV, Barrucand L, Verçosa N, Tibirica E. Preoperative education reduces preoperative anxiety in cancer patients undergoing surgery: Usefulness of the self-reported Beck anxiety inventory. Brazilian J Anesthesiol (English Edition) 2019; 69(1): 1-6.

14. Allu H, Kulkarni M, Dinesh E. Study to determine the effect of oral pregabalin premedication on haemodynamic response to laryngoscopy, intubation and carbon dioxide insufflation during laparoscopic cholecystectomy. Sri Lankan J Anaesthesiol 2019; 27(1): 8-14.

15. Indira P, Raghu R, Swetha A. Effects of preoperative single bolus dose of dexmedetomidine on perioperative hemodynamics in elective laparoscopic cholecystectomy. Ind J Clin Anaes 2019; 6(1): 47-54.

16. Alkhashab RH, Hussein SA, Othman WM. Effect of midazolam, fentanyl \& IV lidocaine to decrease the stress response of laryngoscopy \& ETT intubation. Am Sci Res J Eng Tech Sci (ASRJETS) 2019; 55(1): 162-169.

17. Yadav DK, Pal P. A clinical comparative study of effect of intranasal dexmedetomidine and clonidine on hemodynamic response during laryngoscopy in hypertensive adult patients: A double blinded randomized trial. Papirex Ind J Res 2018; 7(4): 41-43.

18. Kim S, Hwang KM, Park YS, Nguyen TT, Park ES. Preparation and evaluation of non-effervescent gastroretentive tablets containing pregabalin for once-daily administration and dose proportional pharmacokinetics. Int J Pharmaceut 2018; 550(2): 160-169.

19. Yadav R, Mishra RK. Effect of pregaba-lin on preoperative anxiety and postoperative pain in spine sur-gery: A randomized controlled study. J Neuroanaesthesiol Crit Care 2018; 5(1): 8-14.

20. Pol RP, Chopade AR, Naikwade NS. Comparative studies on novel combinations of pregabalin plus venlafaxine with standard diazepam and marketed combination of alprazolam plus sertra-line for anxiety disorders. Anatomical Sci 2018; 1(3): 1-5.

21. Khanna J, Katoch M, Rajpur S. Comparative evaluation of mela-tonin, pregabalin and alprazolam as premedicants for periope-rative anxiety and post operative pain for laparoscopic surgeries. JK Sci 2019; 21(2); 64-71.

22. Polat SB, Kol IÖ, Avci O, Işbir AC, Kaygusuz K, Gürsoy S. Evaluation of preoperative anxiolytic and postoperative anal-gesic effects of pregabalin premedication. Türkiye Klinikleri Tip Bilimleri Dergisi 2019; 39(1): 9-18.

23. White PF, Tufanogullari B, Taylor J, Klein K. The effect of pregabalin on preoperative anxiety and sedation levels: a dose-ranging study. Anesth Anal 2009; 108(4): 1140-1145.

24. Abdou AM, Saleh RS. A comparative study of postoperative effects of two doses of preemptive pregabalin after tibial fracture fixation under spinal anesthesia. Res Op Anesth Intensive Care 2019; 6(3): 266-270.

25. Ibrahim E, Sultan W, Helal S, Abo-Elwafa H. Pregabalin and dexmedetomidine conscious sedation for flexible bronchoscopy: a randomized double-blind controlled study. Minerva Anesth. 2019; 85(5): 487-493. 